in molecular weight, still remained to be solved. Suggested explanations were put forward in terms of internal re-arrangements of the protein chains which upset the ordered arrangement required for a gel bond, or alternatively, that intra-molecular crosslinking occurs progressively on heating under neutral or alkaline conditions, and interferes with subsequent gel formation.

After a brief discussion Dr. A. Courts (British Gelatine and Glue Research Association), in moving a vote of thanks, expressed the appreciation of the staff of the help given to them by Mr. Ward in his term of office. Mr. C. F. C. Simeons (British Gelatine Works, Ltd.), in seconding, added the thanks of the gelatine and glue industry.

Mr. Janus, in opening the discussion on gelation, gave a short paper on "The Formation and Structure of Gelatin Gels". He deseribed the measured properties of gels, the rigidity of the matured gel, the melting-point and the setting time from the sol state, and showed how these depended on solution $p \mathrm{H}$. He emphasized that setting might occur in a short time even at room temperature, whereas the gel rigidity increased over long periods at $0^{\circ} \mathrm{C}$. The melting-point was, however, much less influenced by low-temperature maturing.

The influence of guanidino content on setting time and melting-point was made clear, but not that on low temperature rigidity. Interference with setting can also be secured by alkaline copper solutions which are presumed to interact with the $\mathrm{CO}$ groups of the backbone. An interaction between guanidinium groups and the backbone was therefore postulated as the mechanism of the early stage of setting. To explain the continued growth of rigidity at low temperatures, reversion to the helical structure was suggested, and support was drawn from the optical rotation changes.

Dr. R. Collison (British Baking Industries Research Association) presented a short paper by Dr. G. A. H. Elton and himself on "The Swelling of Starch". In this he described the swelling of the granules in water as the temperature is raised, and effects on the mechanical properties. He also mentioned the action of surface active agents in controlling swelling, probably by forming a hydrophobic layer on the granules.

Mr. D. D. Carruthers (University of Durham) described measurements on gelatin gels at high frequency, and discussed the dependence on temperature of the mechanical properties.

The general discussion was opened by Dr. G. Stainsby (British Gelatine and Glue Research Association), who emphasized the difficulty of establishing precisely the mechanism of gelation. The vote of thanks to Mr. Janus and the other speakers was moved by Mr. E. Bradbury (British Cotton Industry Research Association) and seconded by Dr. A. Jobling (British Glues and Chemicals, Ltd.)

Alan G. Ward

\title{
THE TORRY RESEARCH STATION, ABERDEEN
}

$\mathrm{T}$ HE Torry Research Station in Aberdeen of the Department of Scientific and Industrial Research, which was set up in 1929 , together with its sub-station in Hull, the Humber Laboratory (opened in 1952), carries out research into the problems of fish preservation. The occasion of the open days during June 15-17, when the Station was on show to scientists, equipment manufacturers, the fish industry and the general publie, provided an opportunity both of seeing the range of practically the whole of the research in the United Kingdom into fish technology and also of assessing how the treatment of the fish we eat is likely to change in years to come.

Although the fish industry has changed in numerous ways in the thirty years since Torry was opened, it nevertheless remains largely 'traditional'; there are many small firms, mechanization to any substantial degree is found only in a few factories and, with the exception of deep freezing, the methods of preservation used were familiar to our grandparents. Torry, which has been closely concerned in many of the changes which have occurred, is becoming more and more closely occupied with the technical development of the industry of the future. Changes are occurring at an increasing tempo and the next decade is likely to see a much greater alteration in both techniques and organization than the previous 30 years have done.

One of the major problems concerning our supply of white fish is that about half of it comes from Arctic waters. The fishing grounds are anything from three days to one week's steaming from the Humber ports, on which almost all the long-distance trawlers are based, and this consequently sets a limit to the age of the freshest fish that can be landed. Voyages are on an average of nearly three weeks duration and the fish caught first may therefore be 16-17 days old when it is landed. Cod and haddock, even when properly stored in crushed ice, remain in reasonably good edible condition for only 14-15 days. About $\frac{1}{2}$ per cent per annum of the Aretic catch is in fact condemned at landing as unfit for human consumption. After landing, the vicissitudes of the distribution chain may render passable fish unpleasant and good fish only passable.

Since the Second World War, considerable attention has been paid at Torry to the problem of how to get fresher fish to the consumer. A promising solution is to build a trawler capable of freezing the first third of the catch. That the idea is practicable was shown in a full-scale trial carried out in 1955-56 under Torry's technical supervision and financed jointly by the Distant Water Vessel Owners' Development Committee, the White Fish Authority and H.M. Government. A Grimsby trawler was fitted with vertical plate freezers developed at Torry and capable of operating satisfactorily in the exacting conditions of Arctic fishing, and with a $-30^{\circ} \mathrm{C}$. cold store. The frozen fish was distributed to consumers throughout the country whose reactions were almost universally favourable. The latest development is the design of a vessel of normal size and cost which would show attractive economic advantages over existing highspeed trawlers. Such a vessel would be a trifle slower than the latter, the extra 1-2 knots of which are disproportionately expensive to obtain. It could spend rather longer on the fishing grounds and therefore land a greater weight of fish. The frozen part of 
the eatch could be used to even out the supply from the summer glut to winter dearth.

Another possible way of slowing down the rate of spoilage of fish is to use antibiotics such as chlortetracycline and oxytetracycline. Much of the pioneer work has been earried out in Canada, where their use is now permitted, but they may not yet be used in the United Kingdom. One of the major tasks in hand is to determine the quantities of these substances likely to get into and remain in the flesh after various types of storage, processing and cooking. Even those antibiotics most effective in fish preservation have limitations; there is little difference in the flavour of fish stored in plain water ice and in antibiotic ice up to about the tenth day, so that no more could be done than to keep fish that would otherwise become poor or very poor in a passable, but not really fresh, state.

A recent survey carried out by staff of the Humber Laboratory and workers seconded by the White Fish Authority of the temperatures of fish during distribution from unloading from the trawler to sale from the fishmonger's slab has stimulated considerable interest within the trade and is already bringing about im. provements in practice. It represents another approach to the same problem of how the quality of fish reaching the consumer can be raised. This survey is probably the first large-scale attempt in any country to obtain first-hand field data of this kind. It is typical of much of the work carried out at Torry, since it was made possible only by the co-operation of the industry and was initiated by discussion with representatives of the fish trade.

The Station necessarily supplements such practical applied investigations and development work with a considerable volume of basic research. Thus, a greater understanding is being sought of the detailed structure and composition of fish tissues, and of their behaviour during processing such as freezing and cold storage, smoking and drying. Knowledge is also being acquired of the composition of the bacterial flora of fish and the nature of the species mainly responsible for spoilage. Studies since the War have contributed to improvements in the taxonomy of the marine bacteria mainly concerned and in the building up of a type culture collection now of international reputation.

Solid progress in recent years in the characterization and estimation of the so-called 'extractives' of fish muscle is providing a clearer insight into the autolytic changes that take place immediately after death and during bacterial spoilage. This work is of particular importance in understanding the various physico-chemical changes that occur during dehydration, freezing and subsequent storage of fish, as well as the factors which give rise to different types of spoilage flora under various conditions. Recent years have also seen the accumulation of new knowledge of the main proteins of fish muscle which is serving in particular to explain the causes of textural change during freezing, cold storage and dehydration. Men. tion should be made of the work on the Maillard 'browning' reactions which occur in dehydrated fish muscle.

Considerable attention has been given to the provention of oxidative rancidity in cold-stored fatty fish. Fish fats are highly unsaturated, and frozen fatty fish such as herring remain in really edible condition for a shorter period than white fish. The rate of oxidation of fish fat can be slowed down by 'glazing'; this consists of dipping the frozen fish in water so that a layer of ice is formed around the outside. Drying of fish in cold store hastens the development of rancidity; even more important, therefore, is to store fatty fish under conditions where drying is at a minimurn. Current work on the oxidation process may eventually lead to economic improvements. It has been found that fat oxidation is catalysed by hxmatin pigments in the red lateral muscle which is present in a well-defined form only in fatty fish.

Nevertheless, there are limits to the cold-storage period even of species like cod which contain considerably less than 1 per cent fat in the muscle; the fat becomes oxidized and there are progressive changes in the protein structure common to all fish. Recently, a new method has been devised for assessing the development of toughness in cold-stored fish. This depends upon the fact that although fresh unfrozen muscle can be macerated in dilute formalin solution to give a thick opaque suspension, there is a tendency for the fibres of frozen fish to resist macera. tion and this resistance increases as a function both of storage time and of storage temperature. By determining the amount of light transmitted by the 'soup' of fish fibres produced under standard conditions it has been found possible to relate samples to a standard time/temperature curve. This test, the validity of which requires further checking to cover a number of variables, is so simple that it could easily be adopted by the fish-freezing firms which, with one or two notable exceptions, do not employ scientifically trained staff and do not possess quality control or development laboratories.

Fish freezes more rapidly than it thaws, due to the difference of thermal conductivity ihrough frozen and unfrozen tissue. For example, a block of fillets 4 in. thick may freeze in $4 \mathrm{hr}$. or so but may take $20 \mathrm{hr}$. to thaw out in air at ambient temperatures. A number of firms use large quantities of frozen fish for their products; for example, there is a variety of ready-cooked fish products prepared initially from frozen fish and sold in frozen consumer packs, and the kippering industry uses large amounts of frozen herring when fresh herring is not available. At present, fish is thawed on a large scale, either by merely leaving the frozen blocks in air or by spraying with cold water. The latter method, if it is carelessly carried out, may adversely affect the quality of the product, and both methods are time- and labourconsuming. Attempts by workers in other countries to apply dielectric heating have not been successful, mainly due to 'runaway' heating. This is the condition in which there is progressively increasing absorption of the available power in warm spots in the blocks, which become cooked; this is at the expense of the cooler portions, which remain frozen. Recently this difficulty has been overcome and commercially available equipment has been slightly modified; a pilot plant has boen running at Torry without trouble for the past six months or so. Blocks of frozen fish can be evenly thawed in about $15 \mathrm{~min}$. The technological implications of this work are very wide indeed.

The commercial smoking of fish is still largely carried out in the traditional smoking kiln which was developed during the early Middle Ages. This is merely a chimney in which brined fish is hung and a sawdust and wood-chip fire lighted on the floor. The operation takes anything up to $12 \mathrm{hr}$. or more to complete. The irregularity of natural convection, and the effect of warm humid weather on the functioning 
of the kiln, render fish-smoking an art which is difficult to practise. In 1939 a mechanical kiln was developed at Torry which simplified the process and made it much easier to control. Although the industry was at first slow to adopt the new kilns, an increasing number of firms are now doing so. Intriguing possibilities are, however, now being suggested as a result of basic physical and chemical work on the composition of wood smoke. It has been shown that virtually all the smoke constituents on smoked fish are derived from the invisible vapour phase and not the visible particulate phase. The practicability of smoking fish with 'smokeless' smoke and further developments as well are envisaged.

There is a continuous programme of work at Torry on the improvement of the efficiency of conventional fish-meal plant. Emphasis is put upon methods of increasing production, plant efficiency and nutritive value of the product.

It is important to stress that the high standing of the Torry Research Station within the fish industry itself is very largely due to the considerable amount of consultation and discussion which takes place with the industry and, not less important, the very good relationship built up between individual scientists and various people 'in the trade'. Much of the development and survey work carried out within the past ten years would have been quite impossible without the close and friendly co-operation of the industry; on this personal contact between govern ment research workers and the industry the future development of this relatively undeveloped and traditional industry, without any research organization of its own, depends. G. H. O. Buratess

\section{FISHERY RESEARCH}

$\mathrm{D}$ R. BREDER has prepared a valuable review of work on social grouping in fish*; it also contains new data, though it is sometimes a little difficult to pick these out. He discusses in detail the various types of groups: the aggregation, where the individuals are not 'polarized'; the school, where they are; and the pod, where the fish are in physical contact. These types of groups are illustrated by outstandingly good photographs, those of pods and fish in 'orderly files' being the most interesting.

Descriptions of new work are mainly of the effect of light intensity and colour on a number of species and the analysis of the internal structure of schools. In the experiments on the effect of the wave-length of light the fish were given a choice between different colours, the intensity of the different colours being equated photometrically. No attempt was made, by determining the spectral sensitivity of the fish, to equate the subjective intensity, or intensity as it appeared to the fish. Of particular interest are Dr. Breder's discussions on the leadership of schools, the school as a super-organism and the evolution of schooling behaviour. There is also a section on schooling in terms of cybernetics, where the point is made that the survival of a species which has grouping tendencies should perhaps be considered from the

* Bulletin of the American Museum of Natural History. Vol. 117, Article $6:$ Studies on Social Groupings in Fishes. By C. M. Breder Jr. Pp. 393-482 + plates 70-80. (New York: American Museum of Natural History, 1959.) 1.50 dollars. point of view of how they have got over the danger involved, rather than that such tendencies automatically have survival value.

Dr. Loukashkin's and Dr. Grant's work on Sardinops caerulea*, a species of great commercial importance, has much in common with Dr. Breder's but is more limited in extent. It is again well illustrated with photographs. Like other clupeoids, Sardinops is not an easy subject for experiment, but results have been obtained which show the importance of light for the maintenance of school formation and that fright reactions are elicited by red lights and by flashing white lights. When given the choice between red, green, blue and white light, the fish avoided red and preferred blue and green to white. As in Dr. Breder's work, this technique has a limitation in that the intensities of the different colours were not equated subjectively but only photometrically.

This type of behaviour work, which may be considered important as an aspect of fisheries research, is now being produced in much greater quantity than before the War, and it is particularly welcome to the fisheries research worker when it is concerned with species of commercial importance.

\section{J. H. S. BLAXTER}

* Proceedings of the California Academy of Sciences. Vol. 29 No. 15: Behavior and Reactions of the Pacific Sardine Sardinop caerulea (Girard) Under the Influence of White and Colored Laratiops Darkness. By A.S. Loukashkin and N. Grant Pp. 509-548 Francisco: California Academy of Sciences, 1959.)

\section{THE ONTARIO RESEARCH FOUNDATION}

$\mathrm{T}$ HE annual report of the Ontario Research Foundation for 1958 (pp. 36. Toronto : Ontario Research Foundation, 1959) includes, besides the report of the director, Dr. H. B. Speakman, a summary of the work of the various sections, a list of papers published during the year, the financial statement and details of the Board of Governors and professional and technical staff. There is also a list of grants for postgraduate studies in science for the period 1958-59, for which grants in 1958 totalled 145,204 dollars. In biochemistry three major projects, dealing with the development of an all-temperature biscuit spread for the Defence Research Medical
Laboratories, tea, and the recovery of pure individual amino-acids from wheat gluten after hydrolysis, were completed, and two major studies are in progress under the Rice Mills Fellowship. In chemistry, activity was maintained at a high level. The three-year survey of air pollution of the Hamilton area was completed, while the development of gas chromatography procoeds apace. In a study of factors controlling the crystallinity of polymers, techniques developed for preparing polymers of butane with 50 per cent of crystallinity are being used to study the relation between the type of catalyst and polymer structure. A novel ion-exchange process for recovering ammonia. 